only in the RA population. In RA patients, treatment regimen and Disease Activity Score 28 were recorded.

Results: There were 413 participants (208 RA patients and 205 in the Vo group; mean age, 58 years) enrolled in the study, 349 of whom were female. In RA patients (mean disease duration, 13 years), bone density was significantly lower $(p<0.001$. repeated-measures ANOVA) and Hcy $(p<0.0001$, repeated-measures ANOVA) was higher in comparison with the Vo group during the 7 year study period. In the analysis of change in Hcy level over 7 years, "RA" and "time" were found to interact with each other ( $p=2.58 \mathrm{e}-7$, repeated-measures ANOVA) (figure 1). Multiple linear regression analysis in the RA population revealed a relationship between the level of Hcy and MTX dose at baseline $(p=0.048)$, but no relationship between the level of Hcy and MCV ( $p=0.165)$.

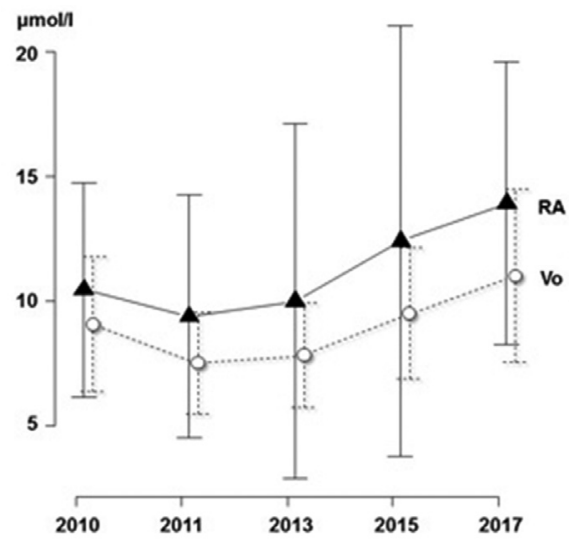

Abstract THU0139 - Figure 1. Homocysteine level during the study period in the patients with rheumatoid arthritis (RA) and healthy volunteer (Vo)

Conclusions: MTX intake leads to folate deficiency, which is thought to cause elevation of the Hcy level. Ageing is another significant factor related to Hcy increase.

Acknowledgements: We thank Atsuko Kamiyama and Tomoko Nakatsuka for serving as research coordinators in terms of recruiting participants, collecting data and managing the quality of the data.

Disclosure of Interest: None declared

DOI: 10.1136/annrheumdis-2018-eular.1439

\section{THU0140 EFFECTS OF STATIN-TREATMENT ON CORONARY PLAQUES IN PATIENTS WITH INFLAMMATORY JOINT DISEASES}

M. Svanteson ${ }^{1,2}$, S. Rollefstad ${ }^{3}$, N.E. Kløw ${ }^{1,4}$, E. Ikdahl ${ }^{3}$, J. Sexton ${ }^{5}$, Y. Haig ${ }^{6}$, A. G. Semb ${ }^{3}{ }^{1}$ Institute of Clinical Medicine, Faculty of Medicine, University of Oslo; ${ }^{2}$ Division of Radiology and Nuclearmedicine, Oslo University Hospital; ${ }^{3}$ Preventive Cardio-Rheuma clinic, Department of Rheumatology, Diakonhjemmet Hospital; ${ }^{4}$ Division of Radiology end Nuclearmediscine, Oslo University Hospital; ${ }^{5}$ Department of Rheumatology, Diakonhjemmet Hospital; ${ }^{6}$ Division of Radiology and Nuclear Medicine, Oslo University Hospital, Oslo, Norway

Background: Statins have an established preventive effect on coronary artery disease in the general population. The effect of statins on coronary plaque progression and characteristics in patients with inflammatory joint diseases (IJD) is unknown.

Objectives: Our aim was to evaluate the change in coronary atherosclerosis in long-term statin-treated patients with IJD.

Methods: Sixty-eight patients with IJD and carotid artery plaque, underwent coronary computed tomography angiography before and after 4.7 (range 4.0-6.0) years of statin treatment. The treatment target for low density lipoprotein cholesterol (LDL-c) was $\leq 1.8 \mathrm{mmol} / \mathrm{L}$. Changes in coronary artery calcification (CAC) and coronary artery plaque volume (calcified, mixed/soft and total) from baseline to follow-up were assessed using the 17-segment model of the American Heart Association. Linear regression analysis was used to identify predictors of atherosclerotic progression.

Results: Coronary plaques were present in $42 \%$ of the patients at baseline and in $51 \%$ at follow up. Mean CAC score increased with $173 \pm 284$, calcified plaque volume with $39.4 \pm 78.3 \mathrm{~mm}^{3}$ and total plaque volume with $22.8 \pm 54.6 \mathrm{~mm}^{3}(\mathrm{p} \leq 0.01$, for all) (figure 1). Mean mixed/soft plaque volume decreased with $-10.4 \pm 27.5$ $\mathrm{mm}^{3}(\mathrm{p} \leq 0.01)$. At follow-up, $51 \%$ of the patients had obtained LDL-c treatment target. Compared to patients above LDL-c target, patients with an LDL-c $\leq 1.8 \mathrm{mmol} /$ L experienced reduced median progression of both CAC $\left(21^{2-143}\right.$ vs. 69 [16-423], $p<0.01)$ and total plaque volume $(0.08[-1.0-13.9]$ vs. $13.0[0.0-60.8], p=0.02)$ (table 1).

\begin{tabular}{|c|c|c|c|}
\hline & $\begin{array}{c}\mathrm{LDL} \leq 1.8 \mathrm{mmol} / \mathrm{L} \\
\mathrm{n}=34\end{array}$ & $\begin{array}{c}\text { LDL }>1.8 \mathrm{mmol} / \mathrm{L} \\
\mathrm{n}=34\end{array}$ & $\begin{array}{c}\mathrm{p}- \\
\text { value }^{*}\end{array}$ \\
\hline LDL-c level baseline, mean $\pm S D$ & $3.7 \pm 0.9$ & $4.4 \pm 1.0$ & $<0.01$ \\
\hline LDL-c level follow-up, mean $\pm S D$ & $1.5 \pm 0.2$ & $2.4 \pm 0.7$ & $<0.01$ \\
\hline Change LDL-c level, mean $\pm S D$ & $-2.2 \pm 0.9$ & $-1.9 \pm 1.3$ & 0.38 \\
\hline Change in CAC, median (IQR) & $21(2-143)$ & $69(16-423)$ & $<0.01$ \\
\hline $\begin{array}{l}\text { Change in soft/mixed plaque volume, } \\
\text { median (IQR) }\end{array}$ & $0(-3.5-0.0)$ & $0(-15.7-0.0)$ & 0.71 \\
\hline $\begin{array}{l}\text { Change in calcified plaque volume, } \\
\text { median (IQR) }\end{array}$ & $1.7(0.0-17.3)$ & $13.4(1.5-107.6)$ & 0.02 \\
\hline $\begin{array}{l}\text { Change in total plaque volume, median } \\
\text { (IQR) }\end{array}$ & $0.08(-1.0-13.9)$ & $13.0(0.0-60.8)$ & 0.02 \\
\hline
\end{tabular}

*independent samples t-test

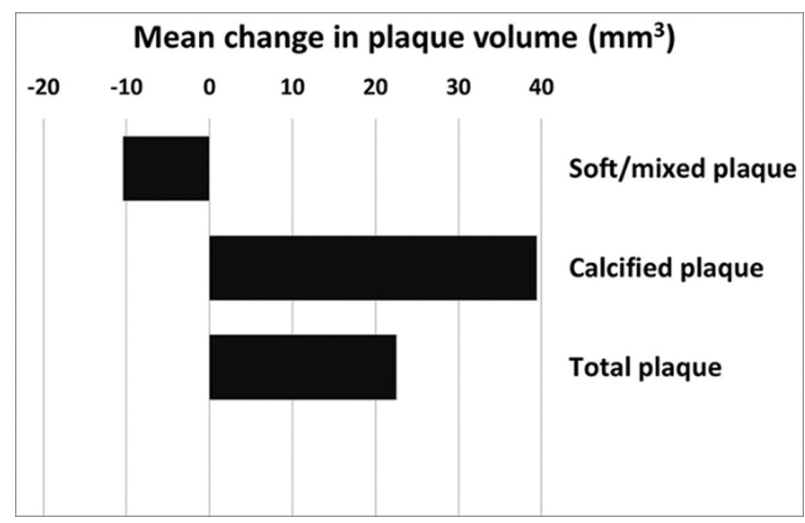

Abstract THU0140 - Figure 1. Mean change in plaque volume $\left(\mathrm{mm}^{3}\right)$

Conclusions: We revealed a progression of atherosclerotic plaque volume in statin-treated patients with IJD, mainly due to calcifications. However, soft, unstable plaques were reduced, probably as a result of an alteration in plaque composition from mixed/soft plaques into calcified plaques. Patients with recommended LDL-c levels at follow-up experienced a reduced atherosclerotic progression compared to patients with LDL-c levels above the treatment target. Our results support the importance of treatment to guideline recommended lipid targets in IJD patients.

Disclosure of Interest: None declared

DOI: 10.1136/annrheumdis-2018-eular.2493

\section{THU0141 LONG-TERM EFFECTS ON BONE MINERAL DENSITY AFTER FOUR YEARS OF TREATMENT WITH TWO INTENSIVE COMBINATION STRATEGIES, INCLUDING INITIALLY HIGH DOSE PREDNISOLONE, IN EARLY RHEUMATOID ARTHRITISPATIENTS: THE COBRA- LIGHT TRIAL}

M.J. Lucassen $^{1,2}$, M.M. ter Wee ${ }^{1,2}$, D. den Uyl ${ }^{1}$, N.P. Konijn ${ }^{1}$, M. T. Nurmohamed ${ }^{1,3}$, D. van Schaardenburg ${ }^{3,4}$, P.J. Kerstens ${ }^{3,5}$, I.E. Bultink ${ }^{1}$, L. H. Van Tuyl ${ }^{1}$, M. Boers ${ }^{1,2}$, W.F. Lems ${ }^{1,3} .{ }^{1}$ Rheumatology; ${ }^{2}$ Epidemiology and Biostatistics, VU University Medical Center, ${ }^{3}$ Rheumatology, Research Institute Reade; ${ }^{4}$ Rheumatology, Amsterdam Medical Center, Amsterdam; ${ }^{5}$ Rheumatology, Westfriesgasthuis, Hoorn, Netherlands

Background: COmbinatie therapie Bij Reumatoide Artiritis (COBRA)-light therapy (methotrexate and initially $30 \mathrm{mg} /$ day prednisolone) has proven to be non-inferior to COBRA therapy (methotrexate, sulfasalazine and initially $60 \mathrm{mg} /$ day prednisolone) in the first year of treatment of early rheumatoid arthritis (RA) patients.

Objectives: This study assessed changes in bone mineral density (BMD) after four years in early RA patients initially randomised to one year of COBRA or COBRA-light therapy

Methods: In the open-label, randomised, non-inferiority trial patients were assigned to COBRA or COBRA-light therapy. After one year, treatment was at the discretion of the treating rheumatologists. BMD in $\mathrm{g} / \mathrm{cm}^{2}$ was measured at baseline, after one, two and four years at total hip, femoral neck, and lumbar spine with dual-energy X-ray absorptiometry (DXA).

Results: Of the 164 original patients, 154 could be assessed after a follow-up of four years (range 34 to 74 months); $68 \%$ were female; mean (SD) age at follow-up $52^{13}$ years. In the COBRA-light group, $11 \%$ of the patients used bisphosphonates after four years; the mean cumulative prednisolone dosage was $2.6 \mathrm{~g}$ (inner quartiles:1.9; 5.9 ) and $49 \%$ of the patients had minimal disease activity (DAS $44<1.6$ ). 